\title{
Methods for Determining the Performance and Efficiency Parameters of the Flue-gas Condenser Sedimentation Tank
}

\author{
Oskars ŠVEDOVS ${ }^{1 *}$, Mik̦elis DZIKĒVIČS ${ }^{2}$, Vladimirs KIRSANOVS ${ }^{3}$ \\ ${ }^{1-3}$ Institute of Energy Systems and Environment, Riga Technical University, Azenes iela 12/1, \\ Riga, LV-1048, Latvia.
}

\begin{abstract}
Flue-gas condenser is used for cleaning the flue-gases in the energy sector. In Latvia, fuel consumption in the household sector is high, so it is planned to introduce this technology in this sector. In the research process of flue-gas condenser, the focus is on reactor testing, rather than on the work of the sedimentation tank - part of the system intended for purification of water from captured particulate matter. In order to ensure good sedimentation process efficiency, it is necessary to know which parameters the process depends on. This study mainly describes the parameters affecting the sedimentation process - dependent indicators and the methods for determining them. The main conclusion is that both methods can be used during the research.
\end{abstract}

Keywords - Flue-gas treatment; fly ash; slurries; scrubbers; sedimentation process; water purification

\begin{tabular}{lll}
\multicolumn{2}{l}{ Nomenclature } & \\
$n$ & Concentration of the substance in the flue-gas (NTP) & $\mathrm{mg} / \mathrm{Nm}^{3}$ \\
$D_{\text {ae }}$ & Aerodynamic diameter (sphere diameter in NTP) & $\mu \mathrm{m}$ \\
\hline
\end{tabular}

\section{INTRODUCTION}

Nowadays different types of fossil fuels, such as heavy or fuel oil and coal, are used less than before. The use of biofuels has seen further development mainly in the household sector. However, while the switch to biofuels has reduced dependency on fossil fuel sources, biofuels face the same problem of creating flue-gas related emissions [1].

Based on the Cabinet of Ministers of Latvia Regulation No. 736 on the emission limit value for biomass, the concentration of fly ash or particulate matter (PM) in the flue-gases shall not exceed $30 \mathrm{mg} / \mathrm{Nm}^{3}$. The emission limit values for other fuels are presented in Table 1 [2].

${ }^{*}$ Corresponding author.

E-mail address: oskars.svedovs@rtu.lv 
TABLe 1. EMission Limit VALUes For EXISTING COMBustion Plants [2]

\begin{tabular}{clcccc}
\hline No. & Fuel type & $\mathrm{SO}_{2}, \mathrm{mg} / \mathrm{Nm}^{3}$ & $\mathrm{NO}_{\mathrm{x}}, \mathrm{mg} / \mathrm{Nm}^{3}$ & $\mathrm{CO}, \mathrm{mg} / \mathrm{Nm}^{3}$ & Fly ash, $\mathrm{mg} / \mathrm{Nm}^{3}$ \\
\hline 1. & Biomass & 200 & 650 & 1000 & 30 \\
2. & Solid fuels (excluding No. 1) & 400 & 650 & 1000 & 30 \\
3. & Diesel (gas oil) & - & 200 & 1000 & - \\
4. & Liquid fuels (excluding No. 3) & 350 & 650 & 300 & 30 \\
5. & Natural gas & - & 200 & 100 & - \\
6. & Gaseous fuels (excluding No. 5) & 35 & 250 & - & - \\
\hline
\end{tabular}

In Latvia, the largest proportion of wood biomass, especially firewood, is consumed in local boiler houses or domestic boilers. For more accurate analysis of consumption data, the energy balance table in the energy section of the central statistical bureau database was used.

By looking at the consumption of wood biomass in the industrial and construction sectors in Latvia and comparing the values of the indicator over the last 8 years (data available from 2010 to 2018) with the consumption of wood in the household sector, it can be concluded that the total consumption of the construction and industrial sectors $(118270 \mathrm{TJ})$ is 1.8 times smaller compared to $208022 \mathrm{TJ}$ in the household sector. In view of the rapid growth in the use of wood pellets in the household sector (36 TJ in 2008 and $1942 \mathrm{TJ}$ in 2018) and the decrease in the consumption of wood, it may be considered that society has acquired sufficient knowledge on the use of more energy-efficient resources and owners of local boiler houses were educated about technological advantages of more efficient boilers. Comparing household wood biomass consumption with natural gas and diesel consumption (Fig. 1) it can be concluded that wood consumption remains much higher than fossil fuel consumption [3].

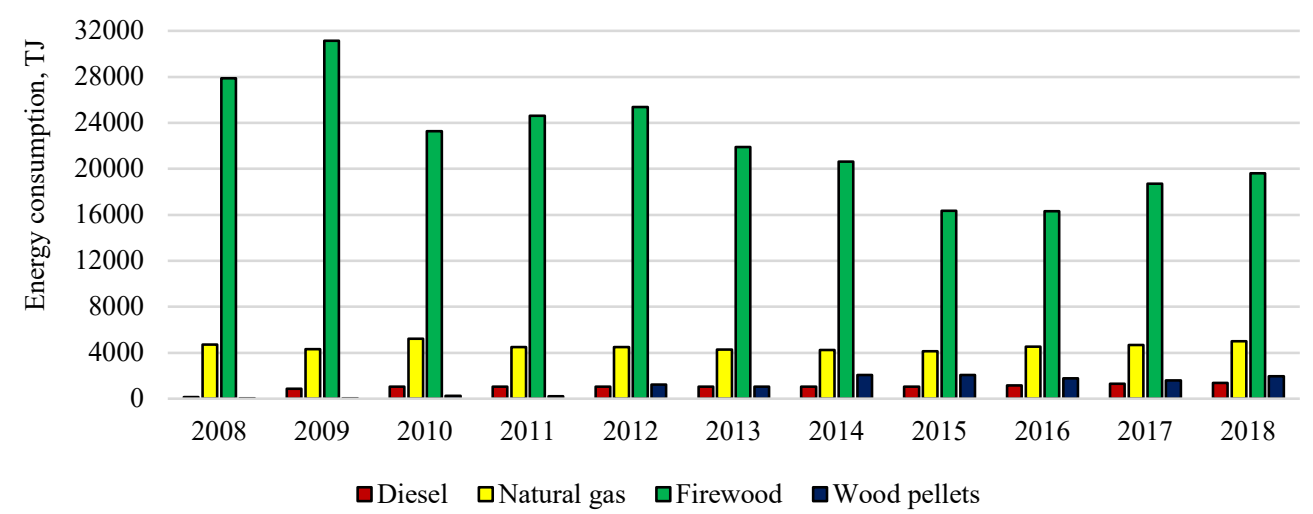

Fig. 1. Consumption of diesel, natural gas and wood biomass (firewood and wood pellets) in the Latvian household sector over 10 years [3].

Emissions of PM from households is currently a problem for Latvia. The above described flue-gas treatment technologies foresee the use of biomass fuels in boilers, while the equipment themselves are intended for use in technical spaces and industrial buildings due to their large size. Various types of pollution, including noise, occur during the lifetime of installations. Considering all types of pollution is an essential step for integrating similar equipment into the household sector. 
There is a problem with the capture of PM from the flue-gas, regardless of the type of fuel. By known standards, airborne pollutants or ultra-dispersive particles are categorised as $\mathrm{PM}_{2.5}$ and $\mathrm{PM}_{10}$; small flying particles (aerosols) of air pollutants with an aerodynamic diameter (sphere diameter in NTP (Normal Temperature and Pressure)) of $10 \mu \mathrm{m}$ and $2.5 \mu \mathrm{m}$ respectively are capable of ignoring the biological protective functions of living organisms and cause harm due to their chemical composition [4].

In order to reduce environmental and air pollution from solid fuel flue-gases, special purification plants based on the principle of absorption or removal of GHG emissions, subsequent precipitation and PM capture should be used. Flue-gas treatment methods are classified according to dry and wet methods [1], [5]. Different types of wet scrubbers are used for cleaning flue-gas from PM. Wet scrubbers are classified in the following categories:

- Venturi scrubber;

- Bubble-column scrubber;

- Water drop tower.

The simplest type of scrubber is a water drop tower, in which flue-gases mix with water drops that are sprayed out of nozzles. The capture of PM is based on two main principles PM is caught by water drops coming in direct contact and through a condensation process. The condensation effect is when the mass of PM increases as water drops on their surface condense. Because of greater weight, the particles fall, creating fly ash slurries. Possible different water spraying conditions depend on flue-gas flow: parallel down or up and perpendicular [6].

The bubble-column scrubber works thanks to the diffusion phenomenon - mixing water in a gaseous state (bubbled) with the flue-gases, creating a uniform mixture of gases. The uniform mixture of gases provides a larger contact area which makes the condensation process the dominant PM capture method in bubble-column scrubbers [6].

Another type of scrubber works after the Venturi effect (reduction of pressure on the part of the tube with a shorter diameter). The water is administered to the scrubber with a nozzle under high pressure (from 3 bar). The flue-gases are released through the water flow. In the middle of the scrubber, the water blends with gases under high pressure. Therefore, it is more likely to contact the drops with the finer PM. Since there is a Venturi effect, pressure decreases as the diameter of the inner wall increases, the majority of PM is precipitating. Since the use of such scrubbers is energy-intensive, water drop towers are used more broadly [6].

A study by Augusto Bianchini et al. [7] describes the efficiency of these wet scrubbers (Fig. 2). Experimentally, the Venturi scrubber was more efficient (60.4\%), but water drop tower - twice less efficient $(28.2 \%)$.

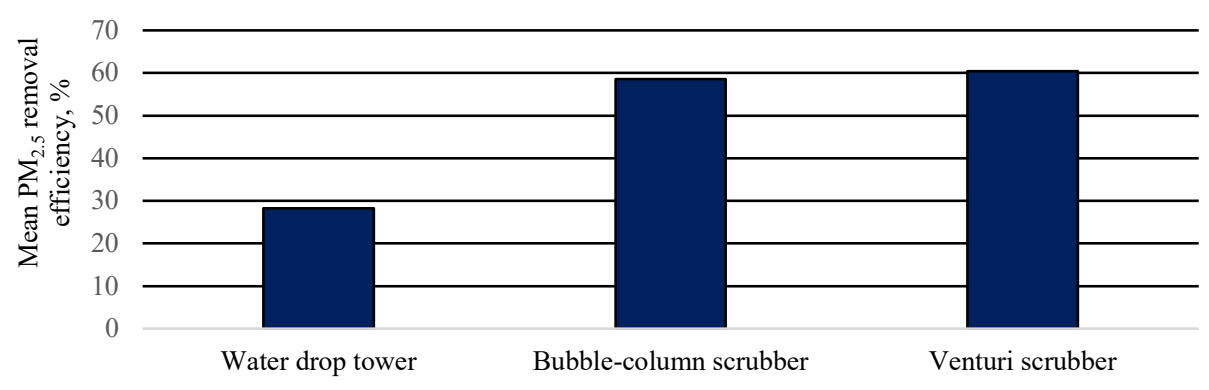

Fig. 2. $\mathrm{PM}_{2.5}$ removal efficiency of different types of wet scrubbers [7]. 
In many countries the use of biomass as a fuel has been increasing in the household sector (especially in winters). This is due to the price increase of other fuels, such as traditional fossil fuels. The promotion of renewable fuels plays a role in this increase, but despite the theoretical $\mathrm{CO}_{2}$ neutrality of biomass, the formation of PM exists [6].

The technology for PM capture in the industrial sector has high investment costs which make application of the same technology within household sector unfeasible. In addition, the authors of the article demonstrate that small scale biomass combustion boilers $(<35 \mathrm{~kW})$ intended for use in private houses produce higher emissions of PM than other boilers that use other types of fuels, e.g. natural gas. The biomass combustion process creates different types of waste:

- Fly ash (inorganic);

- Organic particles (tar);

- Wood ash (solid) - ash that forms in the burner and is collected within the boiler;

- Incomplete combustion residues (soot).

For example, an incomplete combustion of biomass is caused by insufficient or excess air supply in the boiler, low burning temperature or fuel burning time [6].

Unlike PM arising from the combustion process of other fuels, the combustion of biomass results in a higher proportion of $\mathrm{PM}$ emissions consisting of $\mathrm{PM}_{1}$ or particles with an aerodynamic diameter of less than $1 \mu \mathrm{m}$. In addition, in the paper by Johansson et al, it was identified that for a pellet boiler with a capacity of $20 \mathrm{~kW}$ the size of PM is from $0.1 \mu \mathrm{m}$ to $0.2 \mu \mathrm{m}[6]$.

The experimental system of flue-gas condenser located in the Riga Technical University Institute of Energy Systems and Environment (IESE) laboratory is used for research PM capture from the flue-gases of household size wood pellet boiler. The system includes a wood pellet boiler $(20 \mathrm{~kW})$, a small water drop tower, a sedimentation tank and a flue-gas outlet system (Fig. 3). Flue-gases exit the boiler and enter the condenser reactor at the bottom section. The experimental system consists of weights under the boiler for fuel consumption measurement, temperature sensors for all gas and cooling water flows, inlets for flue-gas composition and PM capture probes, flowmeters for calculation of energy balance, gas relative humidity sensors and differential pressure sensors. All the measurements are gathered by a data logging system. Additionally, the system that controls the boiler and its cooling system is used separately from the flue-gas condenser unit. The inlet mass flows are ambient air, cold grid water and fuel, while the outlet flows are hot water, flue-gas and slurry within PM sedimentation system [8].

The operating principle of the system is as follows: the particles in the flue-gases after entering the reactor come into contact with small water drops, are captured by these droplets and they fall to the bottom of the reactor and flow to the sedimentation tank as ash pulp. In this process the water that mixes with flue-gases is heated, therefore after the separation of PM the warm water is pumped through the heat exchanger, obtaining warm water which can be used as pre-heating for hot water preparation. Therefore, additional energy can be recovered, and the overall efficiency of the boiler can be increased. 


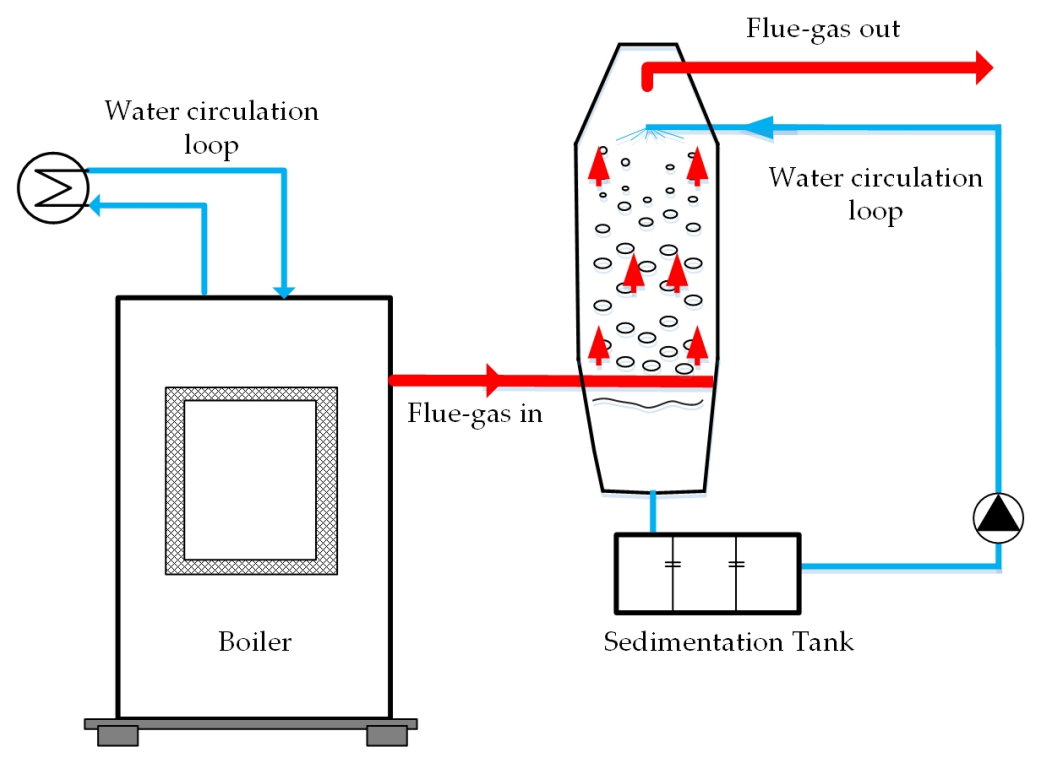

Fig. 3. Schematic of fog unit (without sensors).

Experimental analysis of the system has been carried out and the following parameters obtained:

- Heat output from $0.5 \mathrm{~kW}$ to $5 \mathrm{~kW}$;

- Additional increase in energy efficiency from $2 \%$ to $15 \%$;

- The flowrate of the water that is sprayed out of the nozzle is from $42 \mathrm{l} / \mathrm{h}$ to $344 \mathrm{l} / \mathrm{h}$;

- Pressure before the nozzle from 0.1 bar to 1.7 bar;

- Sprayed water temperature from $20{ }^{\circ} \mathrm{C}$ to $40{ }^{\circ} \mathrm{C}$;

- PM removal efficiency from $30 \%$ to $80 \%$.

The space requirements of the system are one of the barriers. Together with the boiler, the total volume of the experimental structure is $\sim 45 \mathrm{~m}^{3}$ (length $\sim 5 \mathrm{~m}$, width $\sim 3 \mathrm{~m}$, height $\sim$ $3 \mathrm{~m}$ ). Therefore, one of the tasks is to optimize the placement of the components to reduce the necessary space and ideally be placed within the space that is already used by the boiler. Currently, researchers from IESE are experimentally studying the flue-gas treatment with the condenser and defining optimization parameters [9].

During the winter months the boiler works in a continuous manner, therefore the flue-gas treatment system also must be able to work continuously. To have a system where water that catches PM can be recirculated, the water must be cleaned before it is pumped back to the spraying nozzle. Initial experiments are carried out with the sedimentation tank, however as mentioned, space requirements direct, that any component of the system must be optimized in terms of size. Therefore, in this paper, methods for analysing PM removal and parameters that define the efficiency of the system are identified and presented. 


\section{METHODOLOGY}

The water that catches PM in flue-gas is collected at the bottom of the condenser and flows to the filtration system. The water with the PM creates a suspension which needs to be purified by removing the suspended substance from the water.

\subsection{Main parameters describing the sedimentation process efficiency}

Water chemistry field offers many effective methods for the purification of the water, such as multi-cartridge, cartridge and hydrocyclone types of filters, water treatment systems with granulated active coal, etc., but the sedimentation method is more popular, since the filters should be subject to adequate control due to the formation of blockages. The process has low operational and maintenance costs, because sedimentation is provided by physical forces (gravity and hydromechanical), but that makes the process slow [10].

One of the most popular sedimentation tank types is the continuous settler. It can be cubical (the simplest design) or cylindrical. The sedimentation process begins in the first chamber. After a larger size of solid particles precipitate, the shutter lets the water into the next chamber in which the process is repeated. In the last chamber, water is released, purified from larger particles in mixture that can be reused in a wet flue-gas purification plant. The collected suspended substance (depending on its composition) can be used in the future in a useful way, e.g. in a secondary combustion process [11].

Sedimentation tank efficiency describes what part of the incoming mass of ash is separated out of the flow. The efficiency of the sedimentation tank may be determined by:

$$
\eta=\frac{m_{z}}{m_{0}} \cdot 100, \%
$$

where

$\eta \quad$ sedimentation tank efficiency;

$m_{\mathrm{z}}$ mass of the fly ash retained in the sedimentation tank;

$m_{0}$ mass of the fly ash in the water at the inlet to the sedimentation tank.

Using Eq. (1), the system sedimentation efficiency value can be calculated. During the test, a certain fly ash mass is supplied to the water and the configured weights determine the sedimented matter after the end of the test, calculating the efficiency [12].

\subsection{Procedure for experimental determination of sedimentation process efficiency}

The mass of the fly ash collected by the equipment can be determined experimentally in two ways. The first is intended primarily for the determination of the efficiency of the sedimentation tank. In this type of equipment, the suspended substance remains in the sediment position, which can be further collected and weighed. The mass of collected suspended matter can be attributed to the suspended matter mass at the inlet water flow without additional calculation according to the Eq. (1).

The second way of determining the mentioned parameter is for cases when the mass of precipitated suspended matter cannot be determined. This applies mainly to water filters. The mass of the collected suspended matter is determined as the difference between the masses of the suspended substances in the inlet and purified water flow. In that case, the equation for calculating the efficiency will be: 


$$
\eta=\frac{m_{0}-m_{\mathrm{t}}}{m_{0}} \cdot 100, \%
$$

where $m_{\mathrm{t}}$ is the mass of the fly ash in the purified water flow from the sedimentation tank.

The procedure for determining the efficiency of the equipment is as follows:

1. Prepare sample - mixture of water and suspended matter (dried fly ash). Variable factor - the amount of fly ash;

2. Prepare paper filters for vacuum pump system to drain collected water from suspended matter during the experiment. The mass of the paper filters must be determined prior to the experiment;

3. Enter a sample into the inlet pipe of the experimental system;

4. For the sedimentation tank, enter the sample into the unit and empty the tank after a certain time. Collect the sediment. Insert paper filter into vacuum pump system. Release collected suspended matter through a vacuum pump system. Insert a paper filter with the collected suspended matter in the drying oven. Once the sample is dried, weigh it. Calculate the mass of fly ash, which is equals the difference between the masses of the clean paper filter and a paper filter with collected suspended matter. Enter the data in the table (mass of precipitated fly ash). Calculate efficiency using equation (1);

5. For the water filter, release the sample through the equipment. Collect the water that comes out from the equipment. Stop collecting when the water looks clean. Insert paper filter into the vacuum pump system. Release collected water with the suspended matter through a vacuum pump system. Insert a paper filter with the collected suspended matter in the drying oven. Once the sample is dried, weigh it. Calculate the mass of fly ash, which is equal to the difference between the mases of the clean paper filter and a paper filter with collected suspended matter. Enter the data in the table (mass of remaining ash dust). Calculate efficiency using equation (2);

6. The test with the current mass of the fly ash in the water at the inlet, e.g. $0.1 \mathrm{~kg}$, should be repeated at a minimum of three times for each type of test unit.

\subsection{Secondary parameters describing the sedimentation tank performance}

On a conditional basis, the sedimentation tank may be efficient if the water flowing from it is clean. In particular, the efficiency is determined by the volume of purified water flow:

$$
\dot{V}=\frac{V}{\tau}=\frac{S \cdot H}{\tau}
$$

where

$\dot{V} \quad$ volume of purified water flow, $\mathrm{m}^{3} / \mathrm{s}$;

$V \quad$ sedimentation tank volume, $\mathrm{m}^{3}$;

$H$ water height in the sedimentation tank, m;

$S \quad$ settling surface square, $\mathrm{m}^{2}$;

$\tau \quad$ settling time, $\mathrm{s}$.

Settling time may be expressed as:

$$
\tau=\frac{H}{\omega}
$$


where $H$ is water height in the sedimentation tank and $\omega$ is fly ash sedimentation velocity.

Merging Eq. (3) with Eq. (4), the following expression can be obtained:

$$
\dot{V}=\frac{S \cdot H \cdot \omega}{H}=S \cdot \omega
$$

Judging by Eq. (4), it can concluded that the volume of purified water flow can be calculated knowing settling surface square and fly ash sedimentation velocity [13]. The settling surface square may be calculated according to the known dimensions of the sedimentation tank, e.g., if the surface has a rectangular shape, the length must be multiplied by the width.

The fly ash sedimentation velocity can be calculated theoretically using two approaches: water flow simulation and calculation by Stokes Law. Using the Stokes Law (equation (6)) is more appropriate to determine velocity if the parameters can be obtained experimentally.

$$
\omega=\frac{2}{9} \cdot \frac{\left(\rho_{\mathrm{p}}-\rho_{\mathrm{f}}\right)}{\mu} \cdot g \cdot R^{2}
$$

where

$R$ average radius of the fly ash particles, $\mathrm{m}$;

$g$ gravitational field strength, $\mathrm{m} / \mathrm{s}^{2}$;

$\rho_{\mathrm{p}}$ mass density of the fly ash particles, $\mathrm{kg} / \mathrm{m}^{3}$;

$\rho_{\mathrm{f}} \quad$ mass density of the fluid, $\mathrm{kg} / \mathrm{m}^{3}$;

$\mu \quad$ dynamic viscosity, $\mathrm{kg} /(\mathrm{m} \cdot \mathrm{s})$.

If the average radius of the fly ash particles $R$ is less than $0.5 \mu \mathrm{m}$, the Eq. (6) is not appropriate because the particles were exposed to other forces, e.g., Brownian motion. The equation is suitable for particles with the $R$ in the range of $0.5 \mu \mathrm{m}$ to $100 \mu \mathrm{m}$ [14].

Therefore, the value of the average parameter should be used in the equation. In addition, depending on the amount of fly ash in water, the rate of sedimentation may be altered. In the study by Xin Kang et al. it was observed that with higher fly ash concentrations in the water, the fly ash sedimentation velocity parameter is higher [15].

\subsection{Procedure for experimental determination of sedimentation process performance}

The purification performance (volume of purified water flow) of the equipment has been determined to depend on the fly ash sedimentation velocity and settling surface. The purified water flow parameter can be determined theoretically and experimentally. For theoretical calculation, it is necessary to combine Eq. (5) with Eq. (6).

$$
\dot{V}=S \cdot\left(\frac{2}{9} \cdot \frac{\left(\rho_{\mathrm{p}}-\rho_{\mathrm{f}}\right)}{\mu} \cdot g \cdot R^{2}\right)
$$

According to the Eq. (7), it can be concluded that fly ash parameters (particles), unlike fluid (water) parameters, should be determined experimentally. In particular, the experimental determination of the radius and particle density must be carried out. Fly ash samples are required to perform the experiment.

Due to the fly ash particle size, the experimental determination of the sedimentation velocity should be carried out with additional equipment and other conditions. In order to 
calculate the sedimentation velocity of particles in the water, it is necessary to determine their density before that. The density of particles can be calculated by experimental use of Stokes Law. When measuring fly ash sedimentation velocity in a fluid with a higher viscosity and a lower density than water, it is possible to calculate particle density by expressing it from the Eq. (6):

$$
\rho_{\mathrm{p}}=\frac{9 \cdot \mu \cdot \omega}{2 \cdot g \cdot R^{2}}+\rho_{\mathrm{f}}
$$

During the measurement procedure, the following instruments are required:

- microscope $(\times 10$ increase $)$;

- spade;

- hemocytometer;

- chronometer;

- pipette;

- cover glass;

- ethanol $70 \%$;

- distilled water;

- petroleum jelly.

Measurement procedure:

1. Set up an experimental stall. Place the microscope parallel to the table by squeezing it on $90^{\circ} \mathrm{C}$. It is important that the microscope is in stationary mode. Insert and reinforce the hemocytometer into the microscope;

2. Prepare a $70 \%$ solution of ethanol;

3. The three sides of the cover glass (leaving the upper edge clean) must be stained with petroleum jelly and glued to the hemocytometer in such a way that the upper edge of the cover glass is not glued to the surface of the hemocytometer;

4. Pour $8 \mu \mathrm{L}$ of $70 \%$ solution of ethanol between the cover glass and hemocytometer. Make sure that the solution covers the entire surface of the covering glass;

5. Prepare a sample by mixing $70 \%$ solution of ethanol and dried fly ash;

6. Slowly pour fly ash sample under the surface of the cover glass with the pipette;

7. Measure the distance and time of the current particles with the digital equipment of the microscope and write the results into the table.

Knowing the time, it took for a particle to travel the current distance, sedimentation velocity could be calculated by the equation (9):

$$
\omega=\frac{s}{t}
$$

where $s$ is the distance travelled by the particle and $t$ is the travel time.

The microscope must be equipped with a digital interface to determine the radius of the particles. It is not possible to determine this parameter during the sedimentation velocity experiment, so it should be able to get pictures from the microscope. It is important to display a reference line with the current size that will be used as a ruler. We recommend to use the ImageJ application to analyse pictures. The analysis of the pictures with that scientific application shall be carried out in the following procedure:

1. Open the picture file in the ImageJ application. Consider that each visible particle has

a circular outline; 
2. Take the line above the reference line, which was marked with microscope digital equipment;

3. Create a scale by a drawn reference line (Analyse $>$ Set Scale...) indicating the known unit of measure;

4. Draw the selected particle outline with the application tools;

5. Measure the area of an enclosed figure (Analyse $>$ Measure $>$ look at column Area);

6. Calculate the radius of the figure by the equation (10):

$$
R=\sqrt{\frac{S_{\mathrm{p}}}{\pi}}
$$

where $S_{\mathrm{p}}$ is the particle area and $\pi$ is the constant ratio of a circle's circumference to its diameter;

7. Write the resulting radius value in the table.

By knowing the values of particle radius and sedimentation velocity, and the dynamic viscosity and density value of the $70 \%$ solution of ethanol, particle density could be calculated by the Eq. (8). It will be possible to use the calculations obtained in the Eq. (6) for determining the sedimentation velocity of the particles in the water by introducing binding water parameters into the equation: dynamic viscosity and density.

\subsection{Interpreting of results determined by both methods}

According to the Stokes Law, the sedimentation velocity is divided into the positive and negative. A positive value shows that there is a particle sinking and the sedimentation process sets at a certain speed. In this case, it is possible to calculate the potential performance of the sedimentation tank according to the Eq. (5). At a constant sedimentation velocity, purified water flow depends only on settling surface square. Increasing this parameter will also increase the performance of the sedimentation tank. This, in turn, affects high purification efficiency.

The negative value of sedimentation velocity suggests the sinking is not happening. The particles shall come up until they reach the surface of the water. In this case, the performance of the equipment will also be negative because the purified water will contain fly ash. Therefore, the efficiency rate will be lower. In order to increase efficiency, a sedimentation tank must be fitted with a sieve element. Water flows from the equipment must be secondarily cleaned using a water filter.

\section{CONCLUSION}

There are two methods that can be used to determine the parameters of the sedimentation process. The first method is intended for the experimental assessment of the efficiency of the existing sedimentation tank. The second method makes it possible to determine the performance of the existing sedimentation tank, depending on the fly ash parameters. It is also intended to plan the necessary tank parameters during its construction.

The procedures for determining efficiency and performance related parameters are described in the study. The procedures may be valid for researchers engaged in the relevant field. 


\section{ACKNOWLEDGEMENT}

Developed within the framework of the Riga Technical University's Institute of Energy Systems and Environment (IESE) Individual Heating with Integrated Fog System (IFUS) project.

\section{REFERENCES}

[1] Kouravand S., Kermani A. M. Clean power production by simultaneous reduction of NOx and SOx contaminants using Mazut Nano-Emulsion and wet flue-gas desulfurization. Journal of Cleaner Production 2018:201:229-235. https://doi.org/10.1016/j.jclepro.2018.08.017

[2] Cabinet of Ministers Regulations No. 736. Procedures for the Prevention, Limit and Control of the Issue of Air Pollutants From Burning Plants. Latvijas Vestnesis, 249, 2017.

[3] Central statistical bureau database. Energy balance. [Online]. [Accessed: 02.11.2019]. Available: https://data.csb.gov.lv/pxweb/lv/vide/vide_energetika_ikgad/ENG020.px/table/tableViewLayout1/

[4] Khan M. F., Shirasuna Y., Hirano K., Masunaga S. Characterization of $\mathrm{PM}_{2.5}, \mathrm{PM}_{2.5-10}$ and $\mathrm{PM}_{>10}$ in ambient air, Yokohama, Japan. Atmospheric Research 2010:96(1):159-172. https://doi.org/10.1016/j.atmosres.2009.12.009

[5] Dal Pozzo A., Antonioni G., Guglielmi D., Stramigioli C., Cozzani V. Comparison of alternative flue-gas dry treatment technologies in waste-to-energy processes. Waste Management 2016:51:81-90. https://doi.org/10.1016/j.wasman.2016.02.029

[6] Bianchini A., Pellegrini M., Rossi J., Saccani C. Theoretical model and preliminary design of an innovative wet scrubber for the separation of fine particulate matter produced by biomass combustion in small size boilers. Biomass and Bioenergy 2018:116:60-71. https://doi.org/10.1016/j.biombioe.2018.05.011

[7] Bianchini A., Cento F., Golfera L., Pellegrini M., Saccani C. Performance analysis of different scrubber systems for removal of particulate emissions from a small size biomass boiler. Biomass and Bioenergy 2016:92:31-39. https://doi.org/10.1016/j.biombioe.2016.06.005

[8] Priedniece V., Kirsanovs V., Dzikēvičs M., V̄̄gants G̣., Veidenbergs I., Blumberga D. Experimental and analytical study of the flue-gas condenser - fog unit. Energy Procedia 2019:158:822-827.

https://doi.org/10.1016/j.egypro.2019.01.215

[9] Khorrami Z., Banihashemi M. A. Numerical simulation of sedimentation process in reservoirs and development of a non-coupled algorithm to improve long-term modeling. International Journal of Sediment Research 2019:34(3):279294. https://doi.org/10.1016/j.ijsrc.2018.10.003

[10] Luna F. D. T. et al. Fluid dynamics in continuous settler. Chemical Engineering Journal 2019:362:712-720. https://doi.org/10.1016/j.cej.2019.01.088

[11] Ochowiak M., Matuszak M., Włodarczak S., Ancukiewicz M., Krupińska A. The modified swirl sedimentation tanks for water purification. Journal of Environmental Management 2017:189:22-28. https://doi.org/10.1016/j.jenvman.2016.12.023

[12] Ravva S. R., Iyer K. N., Gaikwad A. J. Development of sump model for containment hydrogen distribution calculations using CFD code. Nuclear Engineering and Design 2015:295:429-440. https://doi.org/10.1016/j.nucengdes.2015.10.009

[13] Tikhonov A., Yarnykh T. Technology of Medicines. Golden Pages, NUPU. 2002.

[14] Kang X., Zhao X., Bate B. Sedimentation Behavior of Kaolinite: Salt and Fly Ash Effects. Int. Conferences on Case Histories on Soil Property improvement. Chicago, Illinois. 2013. 